\title{
Determination of Some Chemical Properties of Wild Pear (Pyrus spinosa Forsk.)
}

\author{
Sevgin Özderin *
}

\begin{abstract}
Wild pear plant species Pyrus spinosa Forsk., naturally grown in woodlands in Turkey, are one of the most important wild fruits consumed by local people as food, as well as used for medical purposes. In this study, some chemical properties were determined such as fruit seed and fruit pulp antioxidant and antimicrobial activities, fruit seed fatty acid components of Pyrus spinosa determined, which grow naturally in Ödemiş, İzmir, in the south of Turkey. The qualitative and quantitative analyses of fatty acid components of fruit seed of $P$. spinosa were determined by GC/MS analysis. A total of 16 fatty acids in the fruit seed were found in the analysis results and $44.8 \%$ linoleic acid $(\mathrm{C} 18: 2 \mathrm{n} 6 \mathrm{c})$, $40.5 \%$ oleic acid (C18:1n9c), and 7.6\% palmitic acid (C16:0) components were found in higher proportions. Free radical removal effects of fruit seed and fruit pulp extracts were determined using the DPPH method. The antimicrobial activity of fruit pulp extract of $P$. spinosa was determined by the disk diffusion method against E. coli, $S$. aureus, and $C$. albicans. This study revealed that the fruit pulp and fruit seed of $P$. spinosa, which had a significant level of antioxidant activity, antimicrobial activity, and fruit seed had high levels fatty acids components.
\end{abstract}

DOI: 10.15376/biores.17.1.1659-1669

Keywords: Pyrus spinosa; fatty acid, Antimicrobial; Antioxidant; Human/Environment health

Contact information: Department of Forest, Muğla Sitkı Koçman University, 480800 Muğla, Turkey;

* Corresponding author: sevginozderin@mu.edu.tr

\section{INTRODUCTION}

Turkey has three biogeographical regions called Euro-Siberian, Mediterranean, and Irano-Turanian, as well as their transition zones. Because its climatic and geographical features change within short intervals of space due to its position as a bridge between two continents, Turkey has acquired the character of a small continent from the point of biological diversity. Hence, there are more flora and endemic plant type richness in Turkey than all of Europe (Özhatay et al. 2009; Demir 2013; Şengül et al. 2017). There are more than 12,000 plant taxa that naturally grow in Turkey, and approximately 3,649 of those (one of three) consists of endemic taxa (Güner et al. 2012). As Turkey has diverse climate areas with various ecological conditions, it is on migration routes, and has been a host for many civilizations. Since the first ages, its plant diversity and richness has increased, as gene sources got richer. As a result, Anatolia has very rich fruit types and varieties (Özbek 1977; Özbek 1985; Demir 2013). The term wild fruit is used for plants that grow naturally in a certain region without planting (Chua-Barcelo 2014). Wild fruits can grow in unproductive soils and in extreme conditions; therefore, they have to develop adaptations that are more resistant to natural conditions. They generally are more fertile, resistant to drought, and are smaller. They have more seeds, and fruits that are sour, fibrous, and 
astringent with more secondary metabolites (Smatana et al. 1988). Edible wild fruits have been used as a food source in the world for centuries and are also important locally for their economic return (Doğan et al. 2004). Wild fruits contain various types of antioxidant components such as flavonoids, phenolics, carotenoids, and vitamins; these are accepted as healthy constituents for human health as they prevent the oxidation of macromolecules and decrease the risk of degenerative diseases by reducing oxidative stress (Markham 1982; Prior et al. 2003; Heber 2004; Rangkadilok et al. 2007; Kubola et al. 2011).

One of the wild fruit species that are commonly grown in Anatolia is the wild pear. The wild pear that grows naturally in Turkey is included in the wild pear and almond leaf wild pear taxon Rosaceae family in systematics, within the Pomoideae sub-family inside Pyrus species (Davis 1972; Anşin and Özkan 1993). Although the Pyrus species has more than 80 types (Browicz 1993), new taxons are being detected as time goes by (Aydin Uğurlu and Dönmez 2014). The homeland of wild pear is stated as Anatolia, and its distribution area is Ukraine, South Eastern Europe, and Turkey. Different varieties and forms of this species in the appearance of Carya and brown are found in different regions of Anatolia. Wild pear has completely xerophyte plant characteristics, has small brown hairy branches, leaves in the shape of a small crow, thick thorny branches, and a pile root that goes deep (Dumanoğlu et al. 1999). Wild pear is a species resistant to air pollution and drought. It is common with its various thorn tree species (Crataegus) in the far forests, in arid places, moorlands, and especially in farms that are opened from the forest. It blooms in April, the fruit ripens fully in autumn, color turns brown, and is eaten at that time (Kartal 2013).

The present study used the Pyrus spinosa Forsk. plant, which is in the category of wild fruits from the Rosaceae family. P. spinosa is mainly distributed in the Mediterranean region and Iran (Jovanovic 1972, 1977; Zamani et al. 2012). P. spinosa was selected as the material of this study from its homeland in Anatolia. It has become an extremely attractive plant, as its impacts on health that were forgotten have recently come to light. Due to its almost ubiquitous presence, which is not affected by harsh climatic conditions, the plant is even more attractive. It is a plant that can grow in most regions in Turkey, but is not very appreciated. The following are some of the known properties of wild pear among people: it is good for heart diseases, diarrhea (however, it leads to constipation in case of overconsumption), makes the heart stronger, dilutes and cleans the blood, reduces fever, it is beneficial for the nerve system as a sedative, reduces fatigue, benefits people with asthma and gingival diseases, and is used to treat insect stings (Keçeci 2018).

A review of the literature showed a lack of research about the chemical composition of $P$. spinosa, including the fatty acid components, antimicrobial activity of fruit seed, as well as the antioxidant activity and other properties of fruit pulp. Therefore, the aim of this study was to evaluate the physicochemical properties, fruit seed fatty acid composition, antioxidant, and antimicrobial properties of $P$. spinosa that can be beneficial to the development of nutraceutical and pharmaceutical uses of agro by-products.

\section{EXPERIMENTAL}

\section{Materials}

Plant material

Fruit samples of $P$. spinosa were collected from Izmir, Ödemiş-Bozdag (1050 m to $1110 \mathrm{~m}$ ), Turkey, in 2020 during the fruit ripening period (October). Plant and fruit 
samples were dried by herbarium techniques, and their identification was conducted in Hacettepe University herbarium. The samples were stored in the same herbarium. The harvested samples were analyzed after maturation at room temperature for a week.

\section{Methods}

Method of determination of fatty acid methyl esters content of fruit seed

Wild pear fruits ( $P$. spinosa) and their samples collected were placed in packages and were transferred to the laboratory within the same day without waiting and exposure to sunlight. The seeds were obtained by cutting the fruit meet off the wild pear fruit $(P$. spinosa) using a knife without damaging it, and the seeds were carefully removed from nests with hands. At this stage, the hollow and blackened seeds were separated from intact ones and were not included in the analysis. Fruit pulp and fruit seeds were dried for about 2 weeks in the shade without direct sunlight.

\section{Determination of fatty acid methyl esters content of fruit seed extracts via (FAME) GC/MSD}

The fruit seeds of wild pear that were dried and ground in a mechanical grinder to fine powder before the extraction process with methanol. Briefly, $100 \mathrm{~g}$ the fruit seeds samples weighed into $400 \mathrm{~mL}$ methanol were mixed using an orbital shaker for 1 hour. Then extraction was continued for 10 days at $25^{\circ} \mathrm{C}$. After the extraction, methanol was evaporated in a rotary evaporator to obtain raw extracts. The obtained methanol extracts were dissolved in water, and again they were extracted with various organic solvents according to their increased polarity, first n-hexane followed by ethyl acetate. Then, the solvents were removed, resulting in raw extracts belonging to each solvent. Approximately $100.0 \mathrm{mg}$ of the resulting hexane extract was weighed into a $20 \mathrm{~mL}$ test tube and $10 \mathrm{~mL}$ of hexane was added to it. After vortexing for $5.0 \mathrm{~min}$, KOH solution $(100 \mu \mathrm{L}$ solution in $2 \mathrm{~N}$ methanol) was added. The mouth of the tube was closed and vortexed for a minute. After centrifuging at $4000 \mathrm{rpm}$ for $10 \mathrm{~min}$, the upper phase machinery-Nagel Chromaphil Xtra was filtered through a PTFE - 20/25 $0.20 \mu \mathrm{m}$ filter and then $2.0 \mu \mathrm{L}$ solution was injected into the Agilent 7890A GC-5975C MSD device.

\section{Antimicrobial activity}

Escherichia coli ATCC 25922, Staphylococcus aureus ATCC 6538P, and Candida albicans ATCC 14053 were used in this study. The test microorganisms were obtained from the culture collection of the microbiology laboratory (Department of Biology of the Faculty of Science and Literature, University of Muğla Sitki Koçman). The disk diffusion method was used to determine the inhibition impacts of fruit pulp and fruit seed extract of P. spinosa on E. coli ATCC 25922, S. aureus ATCC 6538P and C. albicans ATCC 14053 (Collins et al. 1995; Murray et al. 1995). From the liquid cultures that reached 0.5 McFarland standard turbidity, about $1000 \mu \mathrm{L}$ were transferred to sterile petris and approximately $20 \mathrm{~mL}$ of Mueller Hinton Agar (Merck) for bacteria, Sabouraud Dextrose Agar (Merck) for C. albicans were transferred, and planting was made by the pour plate technique. The $20 \mu \mathrm{L}$ extracts were then conveniently placed on the agar. Seed extract was directly dissolved in the fruit extract with dimethyl sulfoxide (DMSO) and used in 200 $\mathrm{mg} / \mathrm{mL}$ concentration (Fig. 1). The Petri dishes in which planting was made were incubated for $24 \mathrm{~h}$ at $37 \pm 0.1^{\circ} \mathrm{C}$ for $S$. aureus and E. coli, and 24 to $48 \mathrm{~h}$ at $30 \pm 0.1^{\circ} \mathrm{C}$ for C. albicans. At the end of incubation, the diameters of the inhibition zones formed around the discs were measured in $\mathrm{mm}$. As a negative control, the fruit pulp and fruit seed extract of $P$. 
spinosa was dissolved in DMSO, and for positive control, amoxicillin + clavulanic acid disc (Oxoid) for bacteria, and Nystatin (Oxoid) for C. albicans were used. All of the studies were carried out in triplicates in parallel.

Determination of DPPH free radical removal activity (Radical scavenging activity)

Radical scavenging activities of extracts were determined using the DPPH method (Burits and Bucar 2000). According to this method, $5 \mathrm{~mL}$ of $0.004 \%$ DPPH (2,2-diphenyl1-picryl-hydrazyl-hydrate, Sigma) solution was added to a sample of $50 \mu \mathrm{L}$ solution taken from concentrations of 100, 50, and $25 \mathrm{mg} / \mathrm{mL}$ of DMSO extracts. Samples were incubated for $30 \mathrm{~min}$ at room temperature and absorbance values were measured at a wavelength of $517 \mathrm{~nm}$. DMSO was used as control.

\section{RESULTS AND DISCUSSION}

\section{Fruit Seed Fatty Acid Compositions}

The fruit seed fatty acid methyl esters components of $P$. spinosa were determined both qualitatively and quantitatively using (FAME)GC/MSD system. The fatty acid components were identified based on certified reference standard substances in Wiley 2008 and NIST 2008 libraries, and their amounts were calculated. Results of the analysis obtained were given in Table 1 . When the fatty acid content in the fruit seed of $P$. spinosa was examined, 44.837\%, of linoleic acid (C18:2n6c), 40.524\% of oleic acid (C18:1n9c), and $7.625 \%$ of palmitic acid (C16:0) were obtained as major components (Table 1).

Table 1. Fatty Acid methyl esters Contents in the Fruit Seed of $P$. spinosa via (FAME)GC/MSD Analysis

\begin{tabular}{|c|c|c|}
\hline Compounds & Percentage (\%) & Retention Time \\
\hline Myristic acid & $0.024 \pm 0.002$ & 15.836 \\
\hline Palmitoleic acid & $0.117 \pm 0.013$ & 21.515 \\
\hline Palmitic acid & $7.625 \pm 0.57$ & 22.472 \\
\hline Cis 10 Heptadecenoic acid & $0.058 \pm 0.01$ & 24.630 \\
\hline Margaric acid & $0.071 \pm 0.004$ & 25.581 \\
\hline Linoleic acid & $44.837 \pm 0.001$ & 27.636 \\
\hline Oleic acid & $40.524 \pm 0.207$ & 27.997 \\
\hline Elaidic acid & $0.521 \pm 0.172$ & 28.034 \\
\hline Stearic acid & $2.544 \pm 0.060$ & 28.724 \\
\hline Cis11 Eicosenoic acid & $0.848 \pm 0.058$ & 33.589 \\
\hline Arachidic acid & $2.004 \pm 0.012$ & 34.530 \\
\hline Heneicosanoic acid & $0.042 \pm 0.116$ & 37.276 \\
\hline Behenic acid & $0.438 \pm 0.007$ & 39.940 \\
\hline Tricosanoic acid & $0.077 \pm 0.022$ & 42.506 \\
\hline Tetracosanoic acid & $0.242 \pm 0.11$ & 44.986 \\
\hline Pentacosanoic acid & $0.030 \pm 0.02$ & 47.377 \\
\hline
\end{tabular}

Hazrati et al. (2019) examined the fatty acid components of the fruit seed of $P$. syriaca and $P$. glabra and they determined the linoleic acid $(46.99 \pm 0.37 \%)$ and oleic acid $(41.43 \pm 0.23 \%)$ in the $P$. syriaca samples as main components, while they obtained linoleic acid (C18:2) $46.99 \pm 0.37 \%$ and oleic acid (C18:1) $41.43 \pm 0.23 \%$ in fruit seeds of $P$. glabra at high rates. Other fatty acid components found in higher amounts in $P$. glabra samples were palmitoleic acid, stearic acid, linoleic acid, alpha-linolenic acid, arachidic acid, and 
heneicosanoic acid methyl ester. The fruit seed fatty acid components of $P$. syriaca were palmitic acid, palmitoleic acid, stearic acid, alpha-linolenic acid, arachidic acid, and gondoic acid.

In other studies, in the samples of Pyrus species, it was stated that 11 fatty acid components were found, and the main components were fatty acids and oleic acid (56.80 $\mathrm{g} / 100 \mathrm{~g}$ oil), stearic acid (20.28 g/100 g oil), and palmitic acid (6.39 g/100 g oil) (Yukui et al. 2009). In P. glabra, Hashemi et al. (2018) determined that the linoleic and oleic acid components as main fatty acids. The study by Gornas et al. (2016) determined that in the cultivars of eight pear (Pyrus communis L.) species, the fatty acid components were palmitic acid (6.1 to 8.5\%), oleic acid (27.4 to 38.2\%), and linoleic acid (50.7 to 63.8\%). When the fatty acid content in the fruit seed of $P$. spinosa was evaluated $44.8 \%$ of linoleic acid (C18:2n6c), 40.5\% of oleic acid (C18:1n9c), and 7.6\% of palmitic acid (C16:0) were obtained as major components. The fatty acid main components of $P$. spinosa determined in the present study show similarity to the other studies on other Pyrus species.

\section{Antimicrobial Activity Results of Pyrus spinosa Fruit Extracts}

The antimicrobial activity of the fruit seed and pulp extracts of $P$. spinosa samples was examined. The inhibition zone value in fruit pulp extract was $8 \mathrm{~mm}$ for $S$. aureus. In fruit seed extract, no activity on test strains was determined. The zone of inhibition measurements are given in Table 2, and inhibition zone images are shown in Fig. 1.

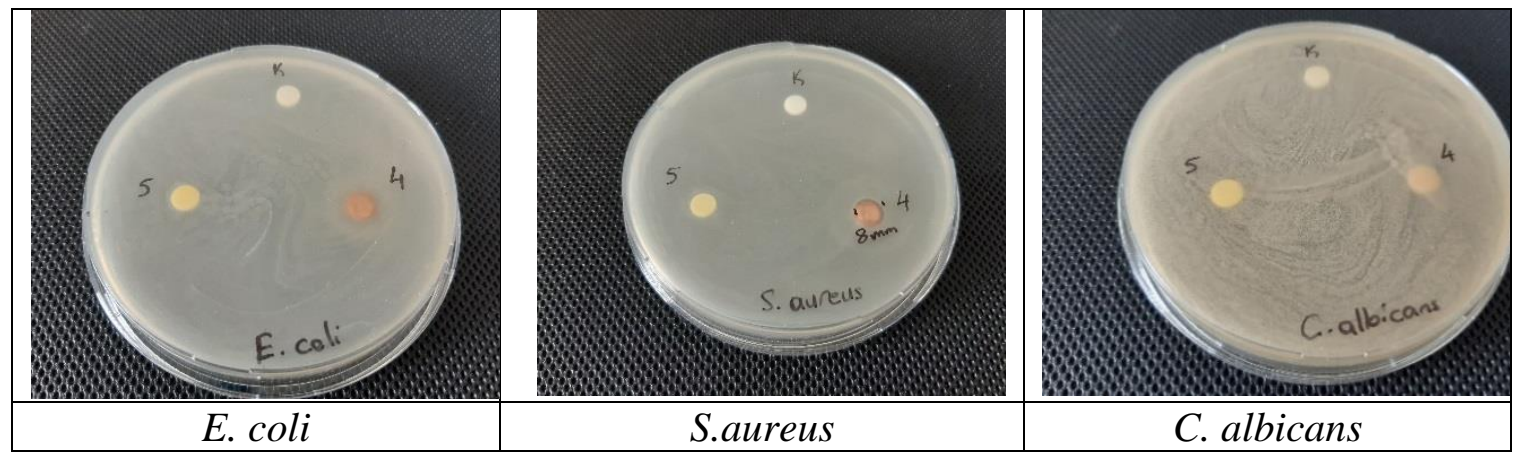

Fig. 1. The results of the antimicrobial activities of $P$. spinosa (Inhibition zone images in the test) (4: fruit extract 5: fruit seed extract, $\mathrm{K}$ : control)

Table 2. Inhibition Zone Diameters of $P$. spinosa Fruit Seed and Fruit Pulp Extracts

\begin{tabular}{|c|c|c|c|c|}
\hline Microorganisms & $\begin{array}{c}\text { Fruit Pulp } \\
\text { Extract }(\mathbf{m m})\end{array}$ & $\begin{array}{c}\text { Seed } \\
\text { Extract }\end{array}$ & $\begin{array}{c}\text { Amoxicillin+Clavulanic } \\
\text { Acid }(\mathbf{m m})\end{array}$ & $\begin{array}{c}\text { Nystatin } \\
(\mathbf{m m})\end{array}$ \\
\hline E. coli & - & - & 16 & Not tried \\
\hline S.aureus & 8 & - & 20 & Not tried \\
\hline C. albicans & - & - & Not tried & 19 \\
\hline
\end{tabular}

In a study conducted in 2012, the antimicrobial activity assay showed 12 bacteria (Aeromonas hydrophila, Bacillus cereus, Bacillus subtilis, Enterobacter cloacae, Escherichia coli, E. coli O157:H7, Klebsiella pneumoniae, Listeria monocytogenes, Proteus vulgaris, Pseudomonas aeruginosa, Salmonella typhimurium, Staphylococcus aureus), and 2 yields (Saccharomyces cerevisiae, C. albicans). The prepared extract showed inhibition effect only on $K$. pneumoniae (10.06 $\mathrm{mm}$ inhibition zone at $10 \%$ concentration) and $A$. hydrophila $(9.56 \mathrm{~mm}$ inhibition zone at $10 \%$ concentration) (Polat 2012). It was found that the aqueous extract of şakok pear (P. elaeagnifolia Pallas) has 
antimicrobial activity at different levels against Streptococcus agalactiae ATCC 13813, Bacillus megaterium DSM 32, S. aureus ATCC 6538, and K. pneumoniae (Murathan et al. 2019). Similar to the results of the present study, Güdücü (2014) found that the 4 different concentrations $(50,100,200,500 \mathrm{mg} / \mathrm{mL})$ of methanol and acetone extracts of fruits of $P$. elaeagnifolia did not form an inhibition zone on 7 bacteria (S. aureus ATCC29213, K. pneumoniae ATCC33495, E. faecalis ATCC29212, P. aeruginosa ATCC27853, E. cloacae ATCC13047, Serratia marcescens, E. coli ATCC25923) and did not exhibit any antimicrobial activity. Erbil et al. (2018) conducted tests on different pear types; it was stated that the highest microbial activity was in banda pear with a $20.14 \mathrm{~mm}$ inhibition diameter against $P$. aeruginosa ATCC 9027, while the lowest activity was in Gügüm pear with a $12.34 \mathrm{~mm}$ inhibition diameter against $E$. coli. In another study, the antimicrobial activity of the wild pear ( $P$. elaeagnifolia) extracts' antimicrobial activities on $S$. aureus, $B$. subtilis, B. cereus, E. coli, L. monocytogenes, and $P$. aeruginosa microorganisms were followed by disk diffusion method. Prepared wild pear leaf extracts were found to show effect at different levels on 6 microorganisms, and they showed high antimicrobial effects against $S$. aureus and E. coli $(18 \pm 1.6 \mathrm{~mm})$ (Keçeci 2018). Various results can be reported in antimicrobial activity and antioxidant studies. These observed differences can be caused by factors such as changes in plant content depending on the climatic conditions and geographical conditions in which the sample grows, different types and/or strains of microorganisms used, and different extraction methods and/or solvent selection methods used.

\section{Antioxidant Activities of Fruit Pulp and Fruit Seed Extracts from Pyrus spinosa Forssk.}

Free radical removal activities of $P$. spinosa extracts were determined using the DPPH method (Burits and Bucar 2000). Table 3 shows the antioxidant activities of the samples. DPPH radical removal activity was observed to vary depending on concentration. High rates of activity were achieved in fruit pulp, while low rates of activity were determined in fruit seeds. The highest activity was found to be $91.2 \%$ in fruit pulp extract. An inhibition of $20 \%$ was determined in the fruit seed at a concentration of $200 \mathrm{mg} / \mathrm{mL}$.

Table 3. Antioxidant Activity of $P$. spinosa Fruit Pulp and Fruit Seed Extracts

\begin{tabular}{|c|c|c|}
\hline Pyrus spinosa Extract & Concentration $\mathbf{( m g} / \mathbf{m L})$ & Radical Removal (\%) \\
\hline \multirow{3}{*}{ Fruit } & 100 & 91.2 \\
\cline { 2 - 3 } & 50 & 90.6 \\
\cline { 2 - 3 } & 25 & 90.1 \\
\hline \multirow{3}{*}{ Seed } & 200 & 20 \\
\cline { 2 - 3 } & 100 & 1 \\
\cline { 2 - 3 } & 50 & 0.0 \\
\cline { 2 - 3 } & 25 & 0.0 \\
\hline Control (Ascorbic acid) & 5 & 93.2 \\
\hline
\end{tabular}

Wild fruits contain high amounts of phytochemicals (Hu 2003; Ikram et al. 2009). Phytochemical studies show that Pyrus species contain such phenolic components as $\beta$ arbutin (Aydin et al. 2015), chlorogenic acid derivatives (Nishimura et al. 2003; Yerliturk et al. 2008), catechin derivatives (Nishimura et al. 2003; Ziyan et al. 2004; Yerliturk et al. 2008, Kim et al. 2013), as well as flavonoids (Siddiq et al. 2000; Dincer et al. 2002), hydroxycinnamoyl acids, and methyl esters (Kostic et al. 2015), caffeoyl triterpenes (Sahu et al. 2013), and sterol glucosides. Wild Pear (Pyrus spp.) is among the widely consumed 
fruits with different species. Various studies indicated that pears contain vitamins and minerals which result in antipyretic, cough-relieving, and diarrhea-relieving properties. It is also reported to be good for urinary system disorders because it affects the liver and menstrual cycle. The leaves of Pyrus communis are urea disinfectant. Wild Pear flowers are used as an analgesic and spasmolytic medication among people (Gudej and Rychlinska 1999). Wild pear leaves with diuretic properties are known to be good for bladder inflammations, bacteriuria, high blood pressure, and the treatment of kidney stones (Zargari 1996). What makes Pyrus spp. important as a diet source is dietary fiber, mineral, vitamin C, and organic acids in it (Chen et al. 2007). In another study, pear is cited as the best source of polyphenols and triterpenes, while also noting the fruit as functional due to its antioxidant and anti-inflammatory effects (Li et al. 2014).

Güven et al. (2006) examined the impact of various pear types (Pyrus spp.) on microorganisms and found that Serik pear (P. serikensis) showed antibacterial effect at certain levels on all bacteria that were examined; however, it was effective on only some of the yeast and mold samples. Pear ( $P$. communis) extract, examined within the context of the same study, was found to prevent the development of all other bacteria and yield except from Salmonella typhimurium, Brucella spp., Streptococcus faecalis, Pseudomonas fluorescens, P. tobacco, P. lachrymans, P. syringae pv. phaseolicola, P. gingeri, and Rhodotorula rubra. However, it was found that it did not have any inhibition impact on molds. Antioxidants can be defined as compounds that, at low concentrations, react with free radicals, thus preventing their oxidation. Many epidemiological studies show that foods rich in antioxidants have a protective effect against diseases, and their consumption reduces the risk of cancer, heart disease, hypertension, and stroke (Polat 2012).

The use of antioxidants to strengthen the body's antioxidant defense system, and prevent or treat diseases. Because of the side effects of synthetic antioxidants, the tendency to use natural antioxidants has increased (Kurutaş 2016). Natural antioxidants are found in different parts of plants, such as roots, stems, leaves, flowers, and fruits. In the present study, the highest antioxidant activity in the samples of $P$. spinosa was found to be $91.2 \%$ in the fruit pulp extract. An inhibition of $20 \%$ was determined in the fruit seed at a concentration of $200 \mathrm{mg} / \mathrm{mL}$.

\section{CONCLUSIONS}

1. This study determined that $P$. spinosa contains phytochemicals important for health. According to the results obtained, it was found that the fruit seed of $P$. spinosa contains high amounts of fatty acid components such as linoleic acid and oleic acid while the fruit pulp of $P$. spinosa contains undetermined fatty acid components. The fruit pulp shows antioxidant activity at high rates and antimicrobial activity in low rates. It was also revealed that the extracts obtained from wild pear contained chemical compounds and as a result of the bioactivity owned by these compounds it can be utilized in medicine and health, and functional food/additives production.

2. In the study, the linoleic acid component was determined at high rates (44\%) in fruit seeds of $P$. spinosa. The double bond structure of the linoleic acid component provides a high rate $(91.2 \%)$ of antioxidant properties, and when compared with the GS-MS analysis results, it has been determined that the results obtained support each other. 


\section{ACKNOWLEDGEMENTS}

The author would like to express their sincere thanks to Prof. Dr. Ali Dönmez from Department of Biology, Faculty of Science in Hacettepe University for identified of the plant materials were performed.

\section{REFERENCES CITED}

Anşin, R., and Özkan, Z. C. (1993). Arboreal Taxons of Seeded Plants (Spermatophyta), Black Sea Technical Unıversity, Forest Faculty, Trabzon.

Aydın Uğurlu, Z., and Dönmez, A. A. (2015). "Taxonomic and nomenclatural contributions to Pyrus L. (Rosaceae) from Turkey," Turkish Journal of Botany 39, 841-849. DOI: 10.3906/bot-1411-34

Browicz, K. (1993). Conspect and Chorology of the Genus Pyrus L. Arboretum Kornickie, 38, 17-33.

Burits, M., and Bucar, F. (2000). "Antioxidant activity of Nigella sativa essential oil," Phytotherapy Research 14, 323-328. DOI: 10.1002/10991573(200008)14:5<323::aidptr621>3.0.co;2-q

Chen, J. L.,Wang, Z. F.,Wu, J. H.,Wang, Q., and Hu, X. S. (2007). "Chemical compositional characterization of eight pear cultivars grown in China," Food Chemistry 104, 268-275. DOI: 10.1016/j.foodchem.2006.11.038

Chua-Barcelo, R. T. (2014). "Ethno-botanical survey of edible wild fruits in Benguet, Cordillera administrative region, the Philippines," Asian Pacific Journal of Tropical Biomedicine 4(Suppl 1), S525-S538. DOI: 10.12980/APJTB.4.201414B36

Collins, P. L.,Mclntosh, K., and Chanock, R. M. (1995). "Collins and Lyne's microbiological methods," Journal of Medical Microbiology 43(4), 310-311.

Davis, P. H. (1972). Flora of Turkey and the East Aegean Islands, Edinburg Universty Press, Edinburg.

Demir, A. (2013). "Rising value in sustainable development; Assessment of Turkey in terms of biodiversity," Istanbul Commercial University Journal of Natural Sciences $12,67-74$.

Dincer, B., Colak, A., Aydin, N., Kadioglu, A., and Güner, S. (2002). "Characterization of polyphenoloxidase from Medlar fruits (Mespilus germanica L., Rosaceae)," Food Chemistry 77(1), 1-7. DOI: 10.1016/S0308-8146(01)00359-4

Doğan, Y., Baslar, S., Ay, G., and Mert, H. H. (2004). "The use of the wild edible plants in Western and Central Anatolia (Turkey)," Economic Botany 58(4), 684-690. DOI: 10.1663/0013-0001(2004)058[0684:TUOWEP]2.0.CO;2

Dumanoğlu, H., Aygün, A., Alay, A., Güneş, N. T., and Özkaya, M. T. (1999). "Rooting and riding in green steels of wild pear (Pyrus elaegrifolia Pall.), the effects of IBA and putrescine," Turkish Journal of Agriculture and Forestry 23, 559-565.

Erbil, N., Murathan, Z. T., Arslan, M., Ilcim, A., and Sayin, B. (2018). “Antimicrobial, antioxidant, and antimutagenic activities of five Turkish pear cultivars ErwerbsObstbau 60(3), 203-209. DOI: 10.1007/s10341-017-0359-1

Gornas, P., Rudzińska, M., Raczyk, M., Mišina, I., Soliven, A., and Segliṇa, D. (2016). "Chemical composition of seed oils recovered from different pear (Pyrus communis L.) cultivars," Journal of the American Oil Chemists' Society 93(2), 267-274. DOI: $10.1007 / \mathrm{s} 11746-015-2768-3$ 
Gudej, J., and Rychlınska, I. (1999). "Chemical compounds in Pyrus communis L. flowers," Acta Poloniae Pharmaceutica 56(3), 237-239.

Güdücü, F. (2014). Pyrus elaeagrifolia: Determination of Phenolic Substance Content, DPPH Radical Removal Activities and Antimicrobial Effects of Pyrus Elaeagrifolia Plant Extracts in Vitro, Master's Thesis, Trakya University, Edirne, Turkey.

Güner, A., Aslan, S., Ekim, T., Vural, M., and ve Babaç, M. T. (2012). "List of plants of Turkey vascular plants," Nezahat Gökyiğit Botanical Garden Botanical Garden and Flora Research Association publication, Istanbul.

Güven, K., Yücel, E., and Cetintaş, F. (2006). "Antimicrobial activites of cretaegus and pyrus species," Pharmaceutical Biology 44, 79-83. DOI: 10.1080/13880200600591253

Hashemi, S. M. B., Khaneghah, A. M., Barba, F. J., Lorenzo, J. M., Rahman, M. S., Amarowicz, R., and Movahed, M. D. (2018). "Characteristics of wild pear (Pyrus glabra Boiss) seed oil and its oil-in-water emulsions: A novel source of edible oil," European Journal of Lipid Science and Technology 120(2), article no. 1700284. DOI: 10.1002/ejlt.201700284

Hazrati, S., Nicola, S., Khurizadeh, S., Alirezalu, A., and Mohammadi, H. (2019). "Physico-chemical properties and fatty acid composition of Chrozophora tinctoria seeds as a new oil source," Grasas Y Aceites 70(4), e328. DOI: 10.3989/gya.0939182

Heber, D. (2004). "Vegetables, fruits and phytoestrogens in the prevention of diseases," Journal of Postgraduate Medicine 50, 145-149.

Hu, F. B. (2003). "Plant-based foods and prevention of cardiovascular disease: An overview," American Journal of Clinical Nutrition 78, 544S-551S. DOI: 10.1093/ajcn/78.3.544S

Ikram, E. H. K., Eng, K. H., Jalil, A. M. M., Ismail, A., Idris, S., Azlan, A., Nazri, H. S. M., Diton, N. A. M., and Mokhtar, R. A. M. (2009). "Antioxidant capacity and total phenolic content of Malaysian underutilized fruits," Journal of Food Composition and Analysis 22, 388-393. DOI: 10.1016/j.jfca.2009.04.001

Jovanović, B. (1972). “Pyrus L.,” in: Flora SR Srbije - IV, M. Josifović (ed.), SANU, Beograd, 133.

Jovanović, B. (1977). “Fam. Malaceae," in: Flora SR Srbije - IV, M. Josifović (ed.), SANU, Beograd, 110.

Kartal, E. (2013). "Use of Wild Pear and Conifer Fruits in High Fiber Grain Products, Master's Thesis, Sakarya University, Sakarya, Turkey

Keçeci, S. (2018). Examination of Some Chemical Properties of Wild Pear (Pyrus elaeagnifolia) Plant Extract Belonging to Afyonkarahisar Büyükkalecik Flora, Master's Thesis, Adnan Menderes University, Aydın, Turkey.

Kim, S. S., Hyun, C. G., Choi, Y. H., and Lee, N. H. (2013). "Tyrosinase inhibitory activities of the compounds isolated from Neolitsea aciculata (Blume) Koidz.," Journal of Enzyme Inhibition and Medicinal Chemistry 28, 685-689. DOI: 10.3109/14756366.2012.670806

Kostic, D. A., Dimitrijević, D. S., Stojanović, G. S., Palić, I. R., Dordević, A. S., and Ickovski, J. D. (2015). "Xanthine oxidase: Isolation, Assays of Activity, and Inhibition," Journal of Chemistry 294858, 8 pages DOI:10.1155/2015/294858.

Kubola, J., Siriamornpun, S., and Meeso, N. (2011). "Phytochemicals, vitamin C and sugar content of Thai wild fruits," Food Chemistry 126, 972-981. DOI:

10.1016/j.foodchem.2010.11.104 
Kurutas, E. B. (2016). "The importance of antioxidants which play the role in cellular response against oxidative/nitrosative stress: current state," Nutrition Journal 15(71), 1-22. DOI: $10.1186 / \mathrm{s} 12937-016-0186-5$

Li, A.-N., Li, S., Zhang, Y.-J., Xu, X.-R., Chen, Y.-M., Li, H.-B. (2014). "Resources and Biological," Activities of Natural Polyphenol s- Nutrients 6(12), 6020-6047. DOI: 10.3390/nu6126020

Markham, K. R. (1982). Techniques of Flavonoid Identification, Academic Press, 1-113, London.

Murathan, Z. T., Erbil, N., Düzgüner, V., and Arslan, M. (2019). "Investigation of antioxidant, antimicrobial and mutagenic properties of Şakok Pear (Pyrus elaeagnifila Pallas)," Journal of Science and Technology-Erzincan University 12(1), 447-456. DOI:10.18185/erzifbed.489779.

Murray, P. R., Baron, E. J., and Pfaller, N. A. (1995). "Manual of clinic microbiology," Trends in Microbiology 3(11), 449-449.

Nishimura, M., Fukuda, C., Murata, M., and Homma, S. (2003). "Cloning and some properties of Japanese pear (Pyrus pyrifolia) polyphenol oxidase, and changes in browning potential during fruit maturation," Journal of the Science of Food and Agriculture 83, 1156-1162.

Özhatay, N., Akalın, E., Ozhatay, E., and Unlu, S. (2009). "Rare and endemic taxa of Apiaceae in Turkey and their conservation significance," Journal of the Faculty of Pharmacy Istanbul 40, 2-15.

Özbek, S. (1985). General Fruit Growing, Çukurova University of Agriculture Faculty Publications, Adana, Turkey.

Özbek, S. (1977). General Fruit Growing, Çukurova University of Agriculture Faculty Publications, Adana, Turkey.

Polat, B. (2012). Investigation of Bioactive Properties of Some Wild Fruits Grown in Kayseri and its Environs, Master's Thesis, Erciyes University, Kayseri, Turkey.

Prior, R. L., Hoang, H., Gu, L., Wu, X., Bacchiocca, M., and Howard, L., (2003). "Assays for hydrophilic and lipophilic antioxidant capacity (oxygen radical absorbance capacity (ORACFL) of plasma and other biological and food samples," Journal of Agricultural and Food Chemistry 51, 3273-3279. DOI: 10.1021/jf0262256

Rangkadilok, N., Sitthimonchai, S., Worasuttayangkurn, L., Mahidol, C., Ruchirawat, M., and Satayavivad, J. (2007). "Evaluation of free radical scavenging and antityrosinase activities of standardized longan fruit extract," Food and Chemical Toxicology, 45, 328-336. DOI: 10.1016/j.fct.2006.08.022

Sahu, J. K., Ganguly, S., Kaushik, A., and Triazoles, A. (2013). "Valuable 1nsight into recent developments and biological activities," Chinese Journal of Natural Medicines $11,456-465$.

Siddiq, M., and Cash, J. N. (2000). "Physico-chemical properties of polyphenol oxidase from D'anjou and Bartlett pears (Pyrus Communis L.)," Journal of Food Processing and Preservation 24(5), 353-364. DOI:10.1111/j.1745-4549.2000.tb00424.x.

Smatana, L., Kytka, J., and Kadarova, S. (1988). "Results of breeding and groving minor fruit species in Czechoslovakia," Acta Horticulture 224, 83-87. DOI:

10.17660/ActaHortic.1988.224.9

Şengül, Ç., and Kaya, S., (2017). "Geographical distribution of endemic plants in Turkey,” Turkish Journal of Geography 69, 109-120. DOI: 10.17211/tcd.322515

Yerliturk, F. U., Arslan, O., Sinan, S., Gencer, N., and Ozensoy, G. O. (2008). "Characterization of polyphenoloxidase from wild pear (Pyrus elaeagrifolia)," 
Journal of Food Biochemistry 32, 368-383. DOI: 10.1111/j.1745-4514.2008.00174.x

Yukui, R., Wenya, W., Rashid, F., and Qing, L. (2009). "Fatty acids composition of apple and pear seed oils," International Journal of Food Properties 12(4), 774-779. DOI: 10.1080/1094291080 2054320

Zamani, A., Attar, F., and Maroofi, H. (2012). "A synopsis of the genus Pyrus (Rosaceae) in Iran," Nordic Journal of Botany 30, 310-332. DOI: 10.1111/j.17561051.2012.00989.x

Zargari, A. (1996). Medicinal Plants, $6^{\text {th }}$ Ed., Tehran University Publications, Tehran, Iran.

Ziyan, E., and Pekyardimci, S. (2004). "Purification and characterization of pear (Pyrus communis) polyphenol oxidase," Turkish Journal of Chemistry 28, 547-557.

Article submitted: September 11, 2021; Peer review completed: January 8, 2022; Revised version received and accepted: January 15, 2022; Published: January 19, 2022.

DOI: $10.15376 /$ biores.17.1.1659-1669 